\title{
Status and Association of BRCA1 and BRCA2 Mutation with Clinicopathological Features in Sudanese Patients with Breast Cancer
}

\author{
Abubaker M. Hamad, Rania M. SidAhmed, Nada S. Haj Mukhtar, \\ Helal G. Alanazi, Hussain G. Ahmed
}

ABSTRACT

Breast cancer is a real problem in Sudan. Onset at early age, presentation with late stage, and limited resources are characterizing national context of breast cancer in Sudan. Histopathology and cytology of breast cancer serve as tool to expand knowledge in order to improve prevention, management and quality of breast cancer patient life. The aim of this study was to find out prevalence of BRCA1 and BRCA2 among Sudanese patients and to investigate the association of BRCA1and BRCA2 genes with clinicopathological features in Sudanese patients with breast cancer. Histopathological procedures were used for preparation of histopathological slides from the tissue blocks from 179 breast cancer patients. One histopathological slide from diseased tissue and another from normal adjacent tissue were used; the normal tissue and the diseased tissue investigated with H\&E stain and molecular biology PCR method on DNA extracted from tissue was used to assess BRCA1 and BRCA2 status. Average age was 41-50 years. Most of cases were females (174 cases) and few males (5cases). Most of cases present were ductal $(150$ cases) in the latter stage (Grade III, 69 cases). Also, most of cases had no lymph node metastasis (161cases). Statistically, there is significant difference in mutations frequency between diseased breast cancer tissue and normal adjacent tissue in regarding for BRCA1 and BRCA2 under investigation (P-value $=0.000$ for the two parameters). Statistically, we found strong significant correlation between the mutations BRCA1 and BRCA2. BRCA1 and BRCA2 had significant correlation with tumor grade; BRCA1 (Pvalue $=0.009)$, BRCA2 $(\mathrm{P}-\mathrm{value}=0.024)$. The results showed that there is no significant correlation between BRCA1 mutation in the diseased tissue and all the following: sex $(P=0.288)$, the age group $(P=0.918)$, the lymph node metastasis $(P=0.971)$, and the histological site of the breast lesion $(P=$ 0.943). Also, there is no significant correlation between BRCA2 mutation in the diseased tissue and all the following: $\operatorname{sex}(P=0.070)$, the age group $(P=$ 0.758), the lymph node metastasis $(P=0.544)$, and the histological site of the breast lesion $(\mathrm{P}=\mathbf{0 . 1 0 3})$. BRCA1 and BRCA2 can be used as diagnostic and prognostic markers, they related to aggressive form of breast cancer specially BRCA2. We recommend for national extensive program of awareness and screening for breast cancer for all Sudanese population along with establishing dataset portal for all cancers to be available for researchers freely.

Keywords: Breast cancer diagnosis, H\&E, PCR, Sudan.
Published Online: February 8, 2022

ISSN: 2684-5199

DOI : $10.24018 /$ ejbio.2022.3.1.309

\section{A. M. Hamad}

Department of Basic Sciences, Preparatory Year Deanship, Prince Sattam Bin Abdulaziz University, Saudi Arabia.

R. M. SidAdmed*

Department of Histopathology and Cytopathology, Faculty of Medical Laboratory Sciences, University of Gezira, Sudan.

(e-mail: raniamahgoub21@gmail.com) N. S. Haj Mukhtar

Department of Pathology, College of Medicine, University of Hail, Saudi Arabia.

H. G. Alanazi

Department of Medical Laboratory Sciences, College of Applied Medical Sciences, Prince Sattam Bin Abdulaziz University, Saudi Arabia.

H. G. Ahmed

Department of Histopathology and Cytology, Faculty of Medical Laboratory Sciences, University of Khartoum, Sudan.

*Corresponding Author

\section{INTRODUCTION}

Globally, breast cancer is the most frequently diagnosed female malignancy. In addition to its heterogeneous nature, breast cancer incidence is increasing worldwide, adding economic burden to both developed and developing countries (Greene and Wilkinson, 2015; Wu et al., 2015). In Sudan, female breast cancer is the leading cancer as it is associated with a high rate of mortality and morbidity (Hamad \& Ahmed, 2016). The etiology of breast cancer has been associated with many risk factors including genetic predisposition; prior personal history and/or familial history of breast or any other cancers; as well as endogenous and/or exogenous hormone levels (e.g. cycle of estrogen up and down levels and using of hormone replacement therapy) are increasing breast cancer risk. Obesity and physical inactivity as well as alcohol consumption contributed to increased risk and death of breast cancer (Padovano et al., 2019). This heterogeneity of each breast cancer case adds major challenges in diagnosis, prognosis, and treatment (Hamad \& Ahmed, 2018). Mutations in the Breast cancer susceptibility gene1 (BRCA1) and Breast cancer susceptibility gene 2 (BRCA2) genes are known to increase the risk of breast cancer for more than $50 \%$ of hereditary mutation. Germline mutations in these genes are associated with $43 \%$ to $84 \%$ of breast cancer risk and up to a $65 \%$ risk for contralateral breast 
cancer. Mutation carriers can go through preventative programs including enhanced surveillance, chemoprevention and/or irreversible surgical interventions (Bayraktar et al., 2015; Brookes, et al., 2015). Defining BRCA1 and BRCA2 mutation status is crucial, because it is a significant predictor of contralateral prophylactic mastectomy (Elsayegh et al., 2015; Neamatzadeh et al., 2015).

Economically developing countries including Sudan, represents about $60 \%$ of breast cancer deaths occur in the world. Contrary, developed countries show decrease mortality due to diagnosis at earlier stage and more options of treatment (Godavarty et al., 2015). Cancer in general is one of the top ten non-communicable diseases that cause both hospital admissions and deaths in Sudan since 1998. Yet, there is no established national program for comprehensive cancer control. The majority of cancer patients in Sudan are diagnosed with advanced degree of cancer where curative treatment is of limited effect (Gafer \& Elhaj, 2014). Breast cancer is the most common malignancy among Sudanese women (Yahia et al., 2014).

High rates of consanguineous marriage is a major factor that influence the family history and the prevalence of BRCA1 and BRCA2 mutations. (Salih et al., 2017; Elbasheer et al., 2019).

Regarding breast cancer in Sudan and according to the global cancer observatory (GCO) which belongs to the world health organization (WHO), total population in Sudan is $41,511,523$. Number of new cases of breast cancer in 2018 in Sudan is 5,677 . Number of deaths due to breast cancer in 2018 in Sudan is 2,935. Number of prevalent of breast cancer cases (5-year) in 2018 in Sudan is 10,607 (The Global Cancer Observatory, 2019).

\section{Definition of Study and Study Area Study Design}

This is a prospective descriptive study to find out the prevalence of BRCA1 and BRCA2 among Sudanese patients with breast cancer and also to detect if any association between BRCA1 and BRCA2 mutations with clinicopathological features in Sudanese patients with breast cancer. The study was conducted in Wad-Madani, Gezira state, Sudan. During the period from January -2015 to August -2016 .

Histopathological procedures were used for preparation of histopathological slides from the tissue blocks from 179 breast cancer patients. One histopathological slide from diseased tissue (group A) and another from normal adjacent tissue (group B) were used; the diseased and the normal tissue from each specimen investigated with $\mathrm{H} \& \mathrm{E}$ stain and molecular biology PCR method on DNA extracted from tissue was used to assess BRCA1 and BRCA2 status.

\section{The ORdinary HaEmatoxylin AND EOSIN (H\&E) STAIN}

The formalin fixed specimens of prostate samples were dewaxed, hydrated in descending grades of alcohol concentration, at $100 \%, 95 \%$ through $70 \%$ to distilled water for 2 minutes in each stage. For staining of the nucleus, the sections treated with Mayer's Haematoxylin for 8 minutes and differentiated by rinsing in acid alcohol for seconds, bluing in running tap water for 8 minutes, counterstaining in Eosin for 1 minute, and rinsed in water. The sections dehydrated in $70 \%$ alcohol through $95 \%$ and $100 \%$ alcohol, and then blotted in a filter paper, cleared in xylene, and mounted in DPX, after that the smears were ready for microscopic examination.

Interpretation of the results: Nucleus; deep blue color. Cytoplasm and background tissue; pink color. RBCs; orange color (Bancrofti et al., 1996).

\section{Molecular Method}

\section{A. DNA Extraction}

The genomic DNA extracted from histopathologic tissue sample. In this, we used G-spin ${ }^{\mathrm{TM}}$ Total DNA Extraction Mini Kit. 17046, 200 columns. Spin type product for extracting high yield and high purified DNA from various specimens including tissue and fixed tissue. We followed the manufacturer instructions.

\section{B. PCR Procedure}

We used Maxime PCR PreMix Kit (i-Taq) from iNtRON Biotechnology, Inc., Gyeonggi-do, Korea. It is dried \& aliquoted PreMix, all-in-one products. All the reagents required for the reaction are in dried pellet in one tube. Immediate PCR by adding template and primer. Gel loading electrophoresis is possible because it contains loading dye. We performed according to manufacturer instructions.

\section{Gel Electrophoresis}

Horizontal Electrophoresis Systems (Bio-Rad Laboratories, Inc., CA, USA) was used for gel electrophoresis according to the manufacturer instructions.

\section{Gel Documentation}

ChemiDoc XRS+ System Imager (Bio-Rad, ChemiDoc XRS+ System, Hercules, California, USA) was used for gel electrophoresis documentation.

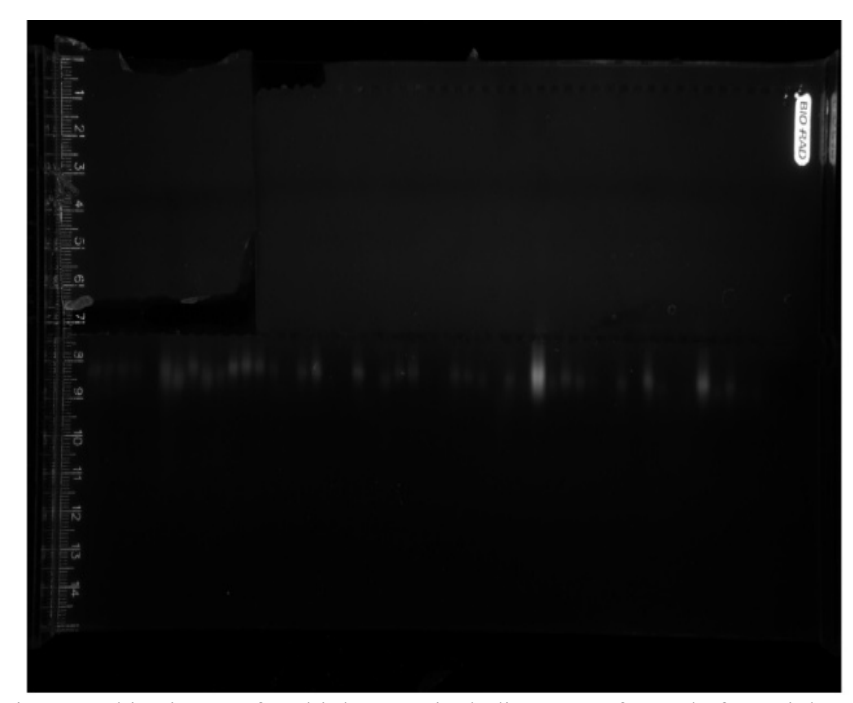

Fig. 1A. This picture of multiple cases including case of sample from right breast of a 70-year-old female diagnosed as grade I infiltrating ductal carcinoma. Bands appear after electrophoresis, (fluorescent band on black background). 


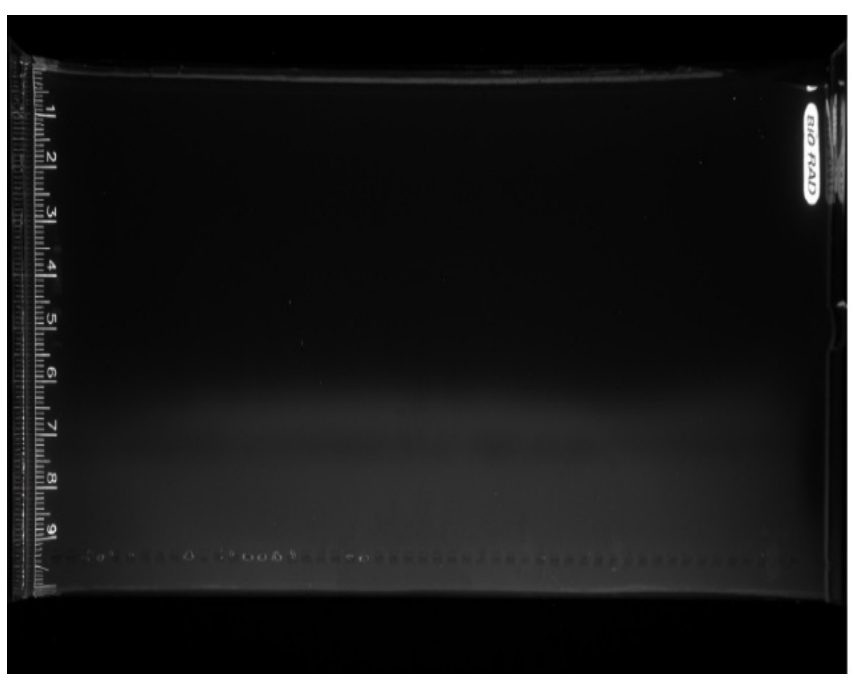

Fig.1B. This is picture of sample from the non-diseased tissue in the margin from the right breast of the same patient. No band appear after electrophoresis, (only black background).

\section{Statistical Analysis}

Statistical tests were done using Statistical Package for Social Science (SPSS) software, version 23. The associations between BRCA1 BRCA2 and between BRCA1\& BRCA2 and demographic data were done. Association between categorical variables was determined by using Chi-square and Fisher Exact tests. The minimum level of significance was set at a $\mathrm{P}$ value $<0.05$.

\section{RESULTS}

\section{A. The Sex of the Study Population}

The sex of the study population includes 174/179(97.2\%) were females and 5/179(2.8\%) were male (Table I).

\begin{tabular}{|c|c|c|}
\hline \multicolumn{2}{|c|}{ Sex } & \multirow{3}{*}{ I lotal } \\
\hline Female & Male & \\
\hline 174 & 5 & \\
\hline
\end{tabular}

\section{B. The Age of the Study Population}

The ages of the entire population of 179 patients was ranging from 13 to 95 years old with mean age of 50.2 years old (Fig. 2).

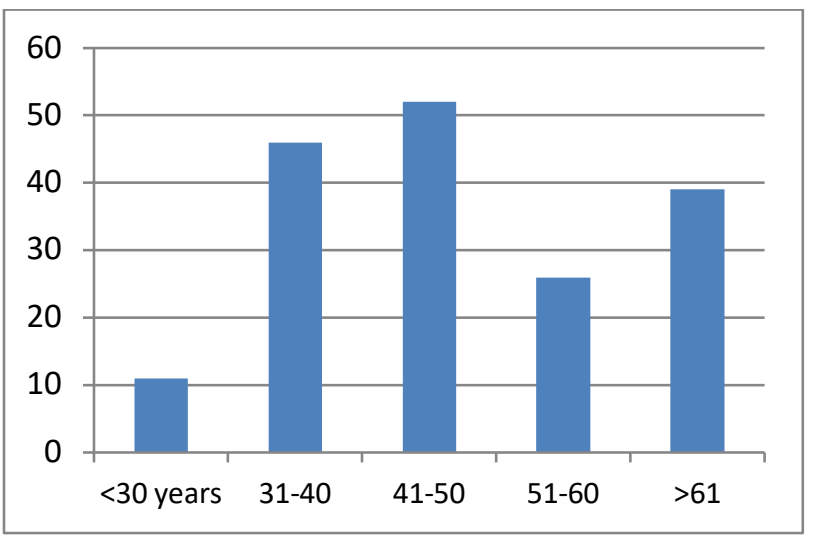

Fig. 2. Distribution of cases by age group.

\section{Diagnosis of the Patients Samples according to Tumor} Type

Malignant tumor diagnosis showed that; ductal carcinoma in situ (DCI) cases were 10/179(5.6\%), invasive ductal carcinoma (IDC) cases were 151/179 (84.4\%), invasive lobular carcinoma (ILC) cases were 6/179(3.4), Sarcoma cases were $9 / 179(5.0 \%)$ and Others were $3 / 179(1.7 \%)$ as shown in Fig. 3

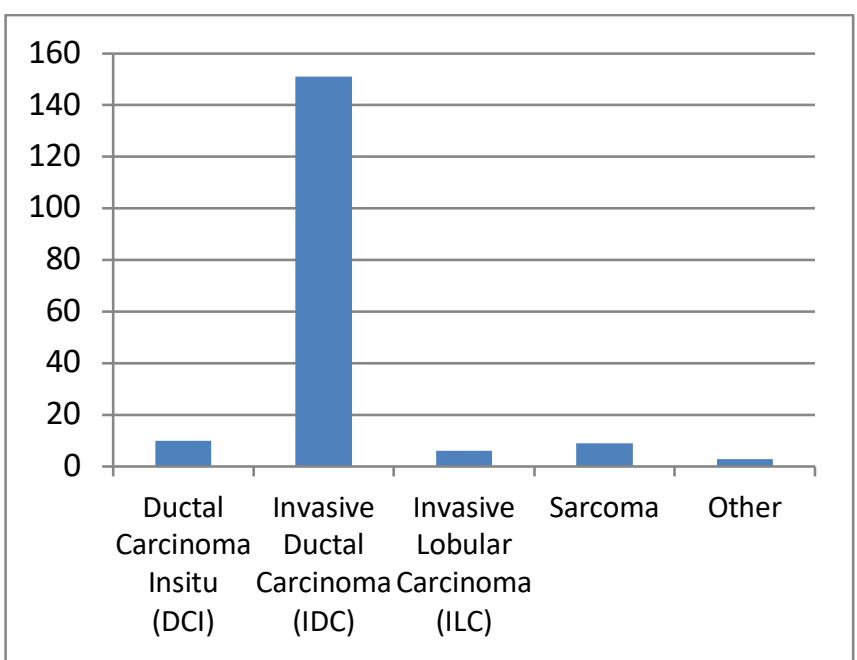

Fig. 3. Distribution of cases according to tumor type.

D. Diagnosis of the Patients Samples according to Tumor Grade

Regarding grade of malignancy, 4/179(2.2\%) was grade I, $74 / 179(41.3 \%)$ was grade II, $69 / 179(38.5 \%)$ were grade III, $41 / 179(0.6 \%)$ was anaplastic, $31 / 179(17.3 \%)$ were have no grade mentioned as shown in Fig. 4.

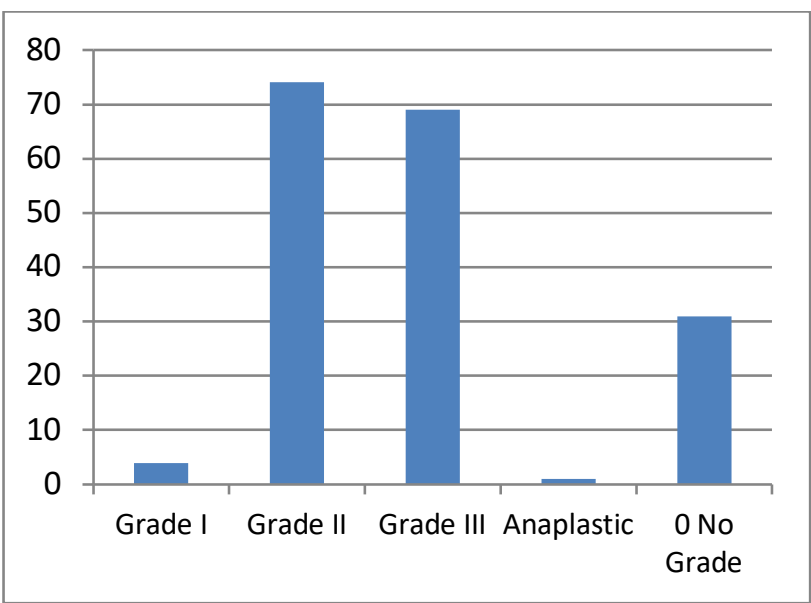

Fig. 4. Distribution of cases by grade of breast cancer.

E. Diagnosis of the Patients Samples according to Lymph Node Metastasis

Lymph node metastasis was found in 18/179(10.1\%) cases, while the rest $161 / 179(89.9 \%)$ showed no lymph node metastasis as shown in Table II.

TABLE II: DISTRIBUTION OF CASES BY LYMPH NODE METASTASIS

\begin{tabular}{ccc}
\hline \hline \multicolumn{2}{c}{ Lymph node metastasis } & Total \\
\hline \hline Absent & Present & 179 \\
\hline \hline 161 & 18 & \\
\hline \hline
\end{tabular}




\section{F. Diagnosis of the Patients Samples according to Histological Sites}

Regarding histological sites, 150/179(83.8\%) were involving the ducts, $17 / 179(9.5 \%)$ were involving lobules, $2 / 179(1.1 \%)$ were involving nipple, $7 / 179(3.9 \%)$ were

TABLE III: DISTRIBUTION OF CASES BY HISTOLOGICAL SITES

\begin{tabular}{ccccccc}
\hline \hline \multicolumn{1}{c}{ Histological site } & & \\
\hline \hline Ductal & Lobular & Nipple (Paget's Disease) & Medullary & Basal cell & $\begin{array}{c}\text { Fibrous } \\
\text { Histio-cytoma }\end{array}$ & $\begin{array}{c}\text { Dermatofibrosarcoma } \\
\text { protuberans }\end{array}$ \\
\hline \hline 150 & 17 & 2 & 7 & 1 & 1 & 1 \\
179 & 1 \\
\hline \hline
\end{tabular}

\section{G. Results of Mutation Tests of BRCA1 and BRCA2}

All histological samples from diseased part of tissue (group A) were investigated for BRCA1 and the results were 40/179(22.3\%) negative, 90/179(50.3\%) low positive and $39 / 179(21.8 \%)$ moderate positive, high positive, and 9/179(5.0\%) high positive and $1 / 179(0.6 \%)$ very high positive (Table IV). Also, they were investigated for BRCA2 and the results were $17 / 179(9.5 \%)$ negative, 55/179(30.7\%) low positive and $64 / 179(35.8 \%)$ moderate positive and $35 / 179(19.6 \%)$ high positive and $8 / 179(4.5 \%)$ very high positive Table IV. (group B) were investigated for BRCA1 and the results were $70 / 179(39.1 \%)$ negative, 78/179(43.6\%) were low positive, $26 / 179(14.5 \%)$ were moderate positive and 5/179(2.8\%) were high positive and $0 / 179(0.0 \%)$ were very high positive (Table V). Also, they were investigated for BRCA2 and the results were $79 / 179(44.1 \%)$ negative, 46/179(25.7\%) were low positive, $27 / 179(15.1 \%)$ were moderate positive and $21 / 179(11.7 \%)$ were high positive and $6 / 179(3.4 \%)$ were very high positive Table IV.
Also, all histological samples from the marginal tissue medullary, $1 / 179(0.6 \%)$ was basal cell, 1/179(0.6\%) was fibrous histiocytoma, $1 / 179(0.6 \%)$ was dermatofibrosarcoma protuberans. as shown in Table III.

\begin{tabular}{ccccc}
\hline \hline & \multicolumn{3}{c}{ Group A } & \multicolumn{2}{c}{ Group B } \\
\cline { 2 - 5 } & BRCA1 & BRCA2 & BRCA1 & BRCA2 \\
\hline \hline Negative & 40 & 17 & 70 & 79 \\
Positive+1 & 90 & 55 & 78 & 46 \\
Positive+2 & 39 & 64 & 26 & 27 \\
Positive+3 & 9 & 35 & 5 & 21 \\
Positive+4 & 1 & 8 & 0 & 6 \\
\hline \hline Total & \multicolumn{5}{c}{179} \\
\hline \hline
\end{tabular}

\section{H. The Relation between BRCA1 and BRCA2 in Diseased} Tissue with BRCAland BRCA2 in the Normal Tissue

The relation between BRCA1 from the diseased tissue and BRCA1 from the marginal tissue. results showed that there is significant difference between BRCA1 mutation in the diseased tissue and BRCA1 mutation in the marginal tissue. $(\mathrm{P}=0.000)$ (Table $\mathrm{V})$.

Also, the relation between BRCA2 from the diseased tissue and BRCA2 from the marginal tissue, the results showed that there is significant correlation between BRCA2 mutation in the diseased tissue and BRCA2 mutation in the marginal tissue. ( $\mathrm{P}=0.000)$ (Table V). BRCA1 and BRCA2 were found more in the malignant tissues, especially BRCA2.

TABLE V: CORRELATION BETWEEN BRCA1 AND BRCA2 GROUP A WITH BRCA1AND BRCA2 GROUP B

\begin{tabular}{|c|c|c|c|c|c|c|c|c|}
\hline \multirow{2}{*}{\multicolumn{2}{|c|}{ Variables }} & \multicolumn{6}{|c|}{ BRCA1 (Group A) } & \multirow{2}{*}{ P-value } \\
\hline & & Negative & Positive +1 & Positive +2 & Positive +3 & Positive +4 & Total & \\
\hline \multirow{6}{*}{$\begin{array}{c}\text { BRCA1 } \\
\text { (Group B) }\end{array}$} & Negative & 24 & 35 & 111 & 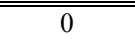 & 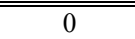 & 70 & \multirow{6}{*}{0.000} \\
\hline & Positive +1 & 13 & 48 & 15 & 1 & 1 & 78 & \\
\hline & Positive +2 & 3 & 7 & 10 & 6 & 0 & 26 & \\
\hline & Positive +3 & 0 & 0 & 3 & 2 & 0 & 5 & \\
\hline & Positive +4 & 0 & 0 & 0 & 0 & 0 & 0 & \\
\hline & \multirow[t]{2}{*}{ Total } & 40 & 90 & 39 & 9 & 1 & 179 & \\
\hline \multirow{7}{*}{$\begin{array}{c}\text { BRCA2 } \\
\text { (Group B) }\end{array}$} & & \multicolumn{6}{|c|}{ BRCA2 (Group A) } & \multirow{7}{*}{0.000} \\
\hline & Negative & 13 & 35 & 27 & 4 & 0 & 79 & \\
\hline & Positive +1 & 3 & 17 & 18 & 8 & 0 & 46 & \\
\hline & Positive +2 & 1 & 2 & 13 & 9 & 2 & 27 & \\
\hline & Positive +3 & 0 & 1 & 5 & 12 & 3 & 21 & \\
\hline & Positive +4 & 0 & 0 & 1 & 2 & 3 & 6 & \\
\hline & Total & 17 & 55 & 64 & 35 & 8 & 179 & \\
\hline
\end{tabular}

\section{The Relation between BRCA1 and BRCA2 in the Diseased Tissue}

The results showed that there was strong correlation between BRCA1 mutation in the diseased tissue with BRCA2 $(\mathrm{P}=0.000)$ from the diseased tissue (Table VI).

TABLE VI: CORRELATION OF BRCA1 AND BRCA2 IN THE DISEASED TISSUE

\begin{tabular}{|c|c|c|c|c|c|}
\hline \multirow{2}{*}{\multicolumn{2}{|c|}{$\begin{array}{l}\text { Variables } \\
\text { Group A }\end{array}$}} & \multicolumn{3}{|c|}{ BRCA1 (Group A) } & \multirow{2}{*}{$\begin{array}{c}\mathrm{P}- \\
\text { value }\end{array}$} \\
\hline & & Negative & Positive & Total & \\
\hline \multirow{3}{*}{ BRCA2 } & Negative & 8 & 9 & 17 & \multirow{3}{*}{0.000} \\
\hline & Positive & 32 & 130 & 162 & \\
\hline & Total & 40 & 139 & 179 & \\
\hline
\end{tabular}

\section{J. The Correlation of BRCA1 Group A with Demographic Data}

The relation between BRCA1 from the diseased tissue with the sex, age group, lymph node metastasis, grade, and histological site. The results showed that there is no significant correlation between BRCA1 mutation in the diseased tissue and all the following: $\operatorname{sex}(\mathrm{P}=0.288)$, the age group $(\mathrm{P}=0.918)$, the lymph node metastasis $(\mathrm{P}=0.971)$, and the histological site of the breast lesion $(P=0.943)$. But the results showed that there is significant correlation between BRCA1 mutation in the diseased tissue and the grade of the breast cancer. $(\mathrm{P}=0.009)$ (Table VII). 


\begin{tabular}{|c|c|c|c|c|c|}
\hline \multirow{2}{*}{\multicolumn{2}{|c|}{ Variables }} & \multicolumn{3}{|c|}{ BRCA1 (Group A) } & \multirow{2}{*}{ P-value } \\
\hline & & Negative & Positive & Total & \\
\hline \multirow{3}{*}{ Sex } & Female & 40 & 134 & 174 & \multirow{3}{*}{0.288} \\
\hline & Male & 0 & 5 & 5 & \\
\hline & Total & 40 & 139 & 179 & \\
\hline \multirow{6}{*}{ Age group } & $<30$ years & 2 & 9 & 11 & \multirow{6}{*}{0.918} \\
\hline & $31-40$ & 12 & 34 & 46 & \\
\hline & $41-50$ & 12 & 40 & 52 & \\
\hline & $51-60$ & 5 & 21 & 26 & \\
\hline & $>61$ & 8 & 31 & 39 & \\
\hline & Total & 39 & 135 & 174 & \\
\hline \multirow{3}{*}{ Lymph node metastasis } & No Lymph Node Metastasis & 35 & 126 & 16161 & \multirow{3}{*}{0.971} \\
\hline & Lymph Node Metastasis & 5 & 13 & 18 & \\
\hline & Total & 40 & 139 & 179 & \\
\hline \multirow{6}{*}{ Grade } & Grade I & 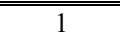 & 3 & 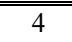 & \multirow{6}{*}{0.009} \\
\hline & Grade II & 26 & 48 & 74 & \\
\hline & Grade III & 8 & 61 & 69 & \\
\hline & Anaplastic & 0 & 1 & 1 & \\
\hline & 0 No Grade & 5 & 26 & 31 & \\
\hline & Total & 40 & 139 & 179 & \\
\hline \multirow{8}{*}{ Histological site } & Ductal & 38 & 1112 & 150 & \multirow{8}{*}{0.943} \\
\hline & Lobular & 0 & 17 & 17 & \\
\hline & Nipple (Paget's Disease) & 0 & 2 & 2 & \\
\hline & Medullary & 1 & 6 & 7 & \\
\hline & Basal cell & 0 & 1 & 1 & \\
\hline & Fibrous Histiocytoma & 1 & 0 & 1 & \\
\hline & $\begin{array}{c}\text { Dermatofibrosarcoma } \\
\text { protuberans }\end{array}$ & 0 & 1 & 1 & \\
\hline & Total & 40 & 139 & 179 & \\
\hline
\end{tabular}

\section{K. The Correlation of BRCA2 group A with Demographic Data}

The relation between BRCA2 from the diseased tissue with the year, sex, age group, lymph node metastasis, grade, and histological site. The results showed that there is no significant correlation between BRCA2 mutation in the diseased tissue and all the following: $\operatorname{sex}(\mathrm{P}=0.070)$, the age group $(\mathrm{P}=0.758)$, the lymph node metastasis $(\mathrm{P}=0.544)$, and the histological site of the breast lesion $(\mathrm{P}=0.103)$. But the results show that there is significant correlation between BRCA2 mutation in the diseased tissue with the grade of the breast cancer $(\mathrm{P}=0.024)$ (Table VIII).

TABLE VIII: CORRELATION OF BRCA2 GROUP A WITH DEMOGRAPHIC DATA

\begin{tabular}{|c|c|c|c|c|c|}
\hline \multirow{2}{*}{\multicolumn{2}{|c|}{ Variables }} & \multicolumn{3}{|c|}{ BRCA2 (Group A) } & \multirow{2}{*}{ P-value } \\
\hline & & Negative & Positive & Total & \\
\hline \multirow{3}{*}{ Sex } & Female & 17 & 157 & 174 & \multirow{3}{*}{0.070} \\
\hline & Male & 0 & 5 & 5 & \\
\hline & Total & 17 & 162 & 179 & \\
\hline \multirow{6}{*}{ Age group } & $<30$ years & 1 & 10 & 11 & \multirow{6}{*}{0.758} \\
\hline & $31-40$ & 3 & 43 & 46 & \\
\hline & $41-50$ & 5 & 47 & 52 & \\
\hline & $51-60$ & 4 & 22 & 26 & \\
\hline & $>61$ & 3 & 36 & 39 & \\
\hline & Total & 16 & 158 & 174 & \\
\hline \multirow{3}{*}{ Lymph node metastasis } & " No Lymph Node Metastasis & 14 & 147 & 161 & \multirow{3}{*}{0.544} \\
\hline & Lymph Node Metastasis & 3 & 16 & 18 & \\
\hline & Total & 17 & 162 & 179 & \\
\hline \multirow{6}{*}{ Grade } & Grade I & 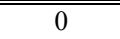 & 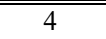 & 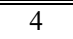 & \multirow{6}{*}{0.024} \\
\hline & Grade II & 8 & 66 & 74 & \\
\hline & Grade III & 6 & 63 & 69 & \\
\hline & Anaplastic & 0 & 1 & 1 & \\
\hline & 0 No Grade & 3 & 28 & 31 & \\
\hline & Total & 17 & 162 & 179 & \\
\hline \multirow{8}{*}{ Histological site } & Ductal & 14 & 136 & 150 & \multirow{8}{*}{0.103} \\
\hline & Lobular & 1 & 16 & 17 & \\
\hline & Nipple (Paget's Disease) & 0 & 2 & 2 & \\
\hline & Medullary & 1 & 6 & 7 & \\
\hline & Basal cell & 0 & 1 & 1 & \\
\hline & Fibrous Histiocytoma & 1 & 0 & 1 & \\
\hline & $\begin{array}{c}\text { Dermatofibrosarcoma } \\
\text { protuberans }\end{array}$ & 0 & 1 & 1 & \\
\hline & Total & 17 & 162 & 179 & \\
\hline
\end{tabular}




\section{DISCUSSION}

Most of cases were females (174 cases) and few males (5cases) (Table I). This agrees with Gucalp et al., (2019).

The average age of the patients in the present study was 41-50 years (29.1\%) (Fig. 2). This agrees with Babiker et al., (2020) and Saleh et al., (2018). Also, Juneja et al., (2019) they found the majority of breast cancer cases are in this age group.

Most of cases present in the latter stage (Grade III, 69 cases) (Fig. 4). This agrees with Galvez et al., (2018) and Sundquist et al., (2017). Also, most of cases had no lymph node metastasis (161cases) (Table II). This agrees with Qiu et al., (2016). Regarding histological sites, most of cases were ductal $(150 / 179,83.8 \%)$ (Table III). This agree Krings and Chen (2018). Most of cases were invasive ductal carcinoma (IDC) $(151 / 179$ (84.4\%) (Fig. 3).

Statistically, there is significant difference in mutations frequency between diseased breast cancer tissue and normal adjacent tissue in regarding for BRCA1 and BRCA2 under investigation ( $\mathrm{P}$-value $=0.000$ for the two parameters) (Table $\mathrm{V}$ and VI). BRCA1 and BRCA2 were found more in the malignant tissues, especially BRCA2 (Table V). Our results agree with Felicio et al., (2017), they performed gene expression analyses for evaluation of BRCA1 expression by RT-qPCR. They found statistically significant difference $(\mathrm{p}<$ 0.0001 ) between the gene expressions of normal samples vs. tumor samples. This difference between diseased breast cancer tissue and normal adjacent tissue was expected due to the malignancy process, which is targeting a specific area, and also indicates etiology of BRCA1 and BRCA2 as a predisposing factor for the breast cancer in Sudanese patients.

Statistically, we found very strong relation between mutations of BRCA1 with BRCA2 $(\mathrm{P}=0.000)$ (Table VI). This because mutagens are targeting multiple genes leading to breast cancer. Our results are similar to Godet and Gilkes, (2017), they stated that absence of an effective repair mechanism allows DNA damage to occur at many sites, including genes required for cell cycle checkpoint expression. For example, genetic mutations in the P53 gene allow BRCAdeficient cells to escape apoptosis and perpetuate. Patients with BRCA1 or BRCA2 mutations frequently harbor TP53 mutations, and it is thought that several oncogenes undergo mutation as a result of BRCA insufficiency.

We also found that BRCA1 had significant correlation with tumor grade $(\mathrm{P}$-value $=0.009)($ Table VII $)$, and also we found significant correlation between BRCA2 with tumor grade (Pvalue $=0.024$ ) (Table VIII). Ha et al., (2017) and Vos et al., (2017) they found just like our study there is strong relation between BRCA1and BRCA2 with grade of breast cancer. Moreover, Ha et al., (2017) and Vos et al., (2017) agreed with our results in that although both BRCA1 and BRCA2 are significantly associated with grade, BRCA2 is less association with grade than BRCA1. These indicates role of BRCA1 mutation in increasing grade of breast cancer and giving more aggressive nature of breast cancer. Juneja et al., (2019) found high rate of BRCA1 mutations i.e. 75\% of grade II patients and $37 \%$ of grade I and grade III, but they did not find correlation between BRCA2 mutations and grade.

Although Guzman-Arocho et al., (2019) found no association between BRCA1 or BRCA2 with grade. This might be due to their selection i.e. they only study young women under age of 40. Also, Gonzalez-Angulo et al., (2011) found no significant correlation between BRCA1 and BRCA2 with grade or histological form. This might be due to selective process as they select only triple negative breast cancer samples while we studied all breast cancer available without discrimination. Identification of breast cancer-related factors, such as cancer type and grade of diagnosis are important determinants of breast cancer overall management and outcomes (Ahmed et al., 2020).

There was no significant correlation between BRCA1 mutation in the diseased tissue and all of the following: sex $(\mathrm{P}=0.288)$, the age group $(\mathrm{P}=0.918)$, the lymph node metastasis $(\mathrm{P}=0.971)$, and the histological site of the breast lesion ( $\mathrm{P}=0.943$ ) (Table VII). These agree with Reiss et al., (2018) for sex and age group, Chen et al., (2020) for lymph node metastasis and histological site, also there was no significant correlation between BRCA2 mutation in the diseased tissue and all the following; sex $(\mathrm{P}=0.070)$, the age group $(\mathrm{P}=0.758)$, the lymph node metastasis $(\mathrm{P}=0.544)$, and the histological site of the breast lesion $(\mathrm{P}=0.103)$ (Table VIII). These agree with Reiss et al., (2018) for sex and age group, Chen et al., (2020) for lymph node metastasis. This indicates these factors are not affecting the clinicopathological outcomes of the breast cancer in Sudanese patients.

\section{CONCLUSION}

Ladies in Sudan still suffer from advanced stages of the breast cancer due to lack of sufficient awareness and screening programs. Most of cases were females (97.2\%). Average age was 41-50 years. Most of cases were ductal in latter stage (Grade III) and there was lymph node metastasis in $(10.1 \%)$ of cases.

There was significant difference in mutations frequency between diseased breast cancer tissue and normal adjacent tissue for both BRCA1 and BRCA2. This indicates the pathogenesis progress and etiology of those parameters as predisposing factor for breast cancer in Sudanese patients.

BRCA1 and BRCA2 had significant correlation with each other and with tumor grade specially BRCA1, indicating their role in aggressive breast cancer. No significant correlation between BRCA1 and BRCA2 with sex, age group or lymph node metastasis thus, no association with clinicopathological outcomes.

\section{ETHICAL CONSIDERATION}

All specimens were retrieved from histopathology department of the Research Laboratory, Faculty of Medicine, Wad-Madani, Gezira State, Sudan after taking their permission and the proposal have been approved by faculty research board, Faculty of Medical Laboratory Science, University of Gezira.

\section{CONFLICT OF INTEREST}

Authors declare that they do not have any conflict of interest. 


\section{AUTHORS' CONTRIBUTIONS}

This research was conducted in collaboration between all authors. All authors involved in the study design, protocol writing, results interpretation and final manuscript draft, reading and approval. Authors AM. H, NS. H, and HG.A preformed the laboratory techniques. Authors AM. H, RM.S, HG.A managed the field data collection and statistical analysis. All authors read and approved the final manuscript.

\section{REFERENCES}

Ahmed, H.G., Elasbali, A.M., AL Gharbi, A.F.A., AL Marshadi, J.A.A., AL Awad, M.N., AL Shammari, M.S.A., et al. (2020). Management and outcomes of women with breast cancer in Hail Region, Northern Saudi Arabia. Medical Science, 24(102), 952-959.

Babiker, S., Nasir, O., Marzogi, A., Bogari, M., Alghamdi, T. (2020). Prospective Breast Cancer Risk Factors Prediction in Saudi Women. Saudi Journal of Biological Sciences. 27(6), 1624-163.

Bancroft, J. D., Layton, C. (2012). The hematoxylins and eosin, Theory and practice of histologic techniques. 173-186

Bayraktar, S., Qiu, H., Liu, D., Shen, Y., Gutierrez-Barrera, A. M., Arun, B. K., et al. (2015). Histopathological Features of Non-Neoplastic Breast Parenchyma Do Not Predict BRCA Mutation Status of Patients with Invasive Breast Cancer. Biomarkers in Cancer, 7, 39-49.

Brookes, C., Lai, S., Doherty, E., Love, D. R., (2015). Predicting the Pathogenic Potential of BRCA1 and BRCA2 Gene Variants Identified in Clinical Genetic Testing. Sultan Qaboos University Medical Journal, 15(2), e218-e225.

Elbasheer, M. M. A., Alkhidir, A. G. A., Mohammed, S. M. A., Abbas, A. A. H., Mohamed, A. O., Bereir, I. M., et al. (2019). Spatial distribution of breast cancer in Sudan 2010-2016. Plos One. 14(9): e0211085.

Elsayegh, N., Profato, J., Barrera, A. M., Lin, H., Kuerer, H. M., Ardic, C., et al. (2015). Predictors that Influence Election of Contralateral Prophylactic Mastectomy among Women with Ductal Carcinoma in Situ who are BRCA-Negative. Journal of Cancer, 6(7), 610-615.

Felicio, P. S., Melendez, M. E., Arantes, L. M., Kerr, L. M., Carraro, D. M., Grasel, R. S., et al. (2017). Genetic and epigenetic characterization of the BRCA1 gene in Brazilian women at-risk for hereditary breast cancer. Oncotarget, 8(2), 2850-2862.

Gafer, N., Elhaj, A., (2014). Palliative care for cancer patients in Sudan: an overview. Ecancer, 8491.

Galvez, M., Castaneda, C. A., Sanchez, J., Castillo, M., Rebaza, L. P., Calderon, G., et al. (2018). Clinicopathological predictors of long-term benefit in breast cancer treated with neoadjuvant chemotherapy. World Journal of Clinical Oncology, 9(2), 33-41.

Godavarty, A., Rodriguez, S., Jung, Y-J., Gonzalez, S., (2015). Optical imaging for breast cancer prescreening. Breast Cancer : Targets and Therapy, 7,193-209.

Godet, I., Gilkes, D. M., (2017). BRCA1 and BRCA2 mutations and treatment strategies for breast cancer. Integrative Cancer Science and Therapeutics, 4(1).

Gonzalez-Angulo, A. M., Timms, K. M., Liu, S., Chen, H., Litton, J. K., Potter, J., et al. (2011). Incidence and outcome of BRCA mutations in unselected patients with triple receptor-negative breast cancer. Clinical Cancer Research, 17(5), 1082-1089.

Greene, L. R., Wilkinson, D. (2015). The role of general nuclear medicine in breast cancer. J Med Radiat Sci, 62, 54- 65.

Gucalp, A., Traina, T.A., Eisner, J. R., Parker, J. S., Selitsky, S. R., Park, B. H., et al. (2019). Male breast cancer: a disease distinct from female breast cancer. Breast Cancer Res Treat, 173, 37-48.

Guzman-Arocho, Y. D., Rosenberg, S. M., Poorvu, P., Ruddy, K. J., Kirkner, G., Snow, C., et al. (2019). Clinicopathological features and BRCA 1/2 status in a large prospective cohort of young women with breast cancer [abstract]. Proceedings of the 2019 San Antonio Breast Cancer Symposium, 2019 Dec 10-14.

Ha, S. M., Chae, E. Y., Cha, J. H., Kim, H. H., Shin, H. J., Choi, W. J. (2017). Association of BRCA mutation types, imaging features, and pathologic findings in patients with breast cancer with BRCA1 and BRCA2 mutations. American Journal of Roentgenology, 209(4), 920-928.

Hamad, A. M., Ahmed, H. G. (2016). Association of connective tissue fibers with estrogen expression in breast lesions among Sudanese females. Int Clin Pathol J, 2(5), 97-102.

Hamad, A. M., \& Ahmed, H. G. (2018). Association of some carbohydrates with estrogen expression in breast lesions among Sudanese females. Journal of Histotechnology, 41(1), 2-9.
Juneja, K., Varshney, A., Kumar, R., Singla, M., Sharma, P., Sharma, V. K. (2019). BRCA1 expression and its association with histological typing, grade, ER, PR, HER2 in carcinoma of breast. Indian J Pathol Oncol, 6(3), 376-80

Krings, G., Chen, Y. (2018). Genomic profiling of metaplastic breast carcinomas reveals genetic heterogeneity and relationship to ductal carcinoma. Mod Pathol, 31, 1661-1674.

Neamatzadeh, H., Shiryazdi, S. M., Kalantar, S. M. (2015). BRCA1 and BRCA2 mutations in Iranian breast cancer patients: a systematic review. Journal of Research in Medical Sciences, 20(3), 284-293.

Padovano, F., Mariani, G., Ferdeghini, M. (2019). Hybrid Imaging for Breast Malignancies. Nuclear Medicine Textbook.

Qiu, S. Q., Zeng, H. C., Zhang, F., Chen, C., Huang, W. H., Pleijhuis, R. G., et al. (2016). A nomogram to predict the probability of axillary lymph node metastasis in early breast cancer patients with positive axillary ultrasound. Scientific Reports, 6, 21196.

Reiss, K. A., Yu, S., Judy, R., Symecko, H., Nathanson, K. L., Domchek, S. M. (2018). Retrospective Survival Analysis of Patients With Advanced Pancreatic Ductal Adenocarcinoma and Germline BRCA or PALB2 Mutations. JCO Precision Oncology, 2, 1-9.

Saleh, H., Rageh, T., Alhassanin, S., Megahed, M. (2018). Upper limb lymphedema related to breast cancer therapy: incidence, risk factors, diagnostic techniques, risk reduction and optimal management. International Surgery Journal, 5(11), 3633-3639.

Salih, A. M., Alam-Elhuda, D. M., Alfaki, M. M., Yousif A. E., Nouradyem M.M. (2017). Developing a risk prediction model for breast cancer: a Statistical Utility to Determine Affinity of Neoplasm (SUDAN-CA Breast). Eur J Med Res, 22, 35.

Sundquist, M., Brudin, L., Tejler, G., (2017). Improved survival in metastatic breast cancer 1985-2016. Breast, 31, 46-50.

The Global Cancer Observatory. 2019. Available from: http://gco.iarc.fr/today/data/factsheets/populations/729-sudan-factsheets.pdf

Vos, S., Moelans, C. B., van Diest, P. J. (2017). BRCA promoter methylation in sporadic versus BRCA germline mutation-related breast cancers. Breast Cancer Res, 19, 64.

Yahia, Z. A., Adam, A. A., Elgizouli, M., Hussein, A., Masri, M. A., Kamal, M., et al. (2014). Epstein Barr virus: a prime candidate of breast cancer aetiology in Sudanese patients. Infectious Agents and Cancer, 9, 9. 